\title{
The Interface of Loneliness, Hospitalization and Illness
}

\author{
Ami Rokach* \\ Center for Academic Studies, Israel \\ *Corresponding author: Ami Rokach, York University, Canada \& Center for Academic Studies, Israel, Email: arokach@yorku.ca \\ Submission: 眥 March 23, 2018; Published: 眥 May 24, 2018
}

\section{Opinion}

This article reviews the experience of loneliness and how it is influenced, and influences, the ill person and the hospitalized individual. Social ties enhance the immune system and help individuals cope with stress and illness. Loneliness has physical, emotional, and cognitive negative effects. Loneliness, which can involve both excruciating physical and mental suffering, is an ancient nemesis. Loneliness is implicated in numerous somatic, psychosomatic, and psychiatric diseases [1]. It is a mundane yet arcane human affliction that is often hazardous to health and hostile to happiness [2]. In this article, I review the experience of loneliness as it affects us when we are not doing well, such as when we are ill or hospitalized.

Sullivan [3] observed that, "For the past 200 years, medicine has pursued the positivist goal of erasing the subject from medical perception. A fully objective view of disease was made possible when the autopsy was integrated into clinical medicine through clinico-pathological correlation...The observed body became the project of modern medicine" (p. 1596). An autopsy is done not for the deceased's sake but for the disease's and the cure's sake. Death has provided medicine with a clear "enemy." Medical research has focused on conquering death-causing diseases. That goal gave medicine social prestige and almost unending funds. Physicians are perceived as possessing supernatural abilities in their fight against serious diseases and death [3]. It is only lately that are we becoming more aware of the importance of considering who the patient is. Mijuskovic [4] maintained that No one is completely selfsufficient and, thus, could not exist without the society in which he lives, and that his happiness is closely related to the community to which he belongs. Loneliness is a universal experience shared by all humans. Being a uniquely subjective experience, it is caused by the individual's personality, environmental and social changes, and his history [5]. That history includes, of course, the illnesses and the cultural context of those illnesses that one may have been afflicted with.

\section{Illness}

Leventhal et al. [5] suggested that there are five components to how people conceptualize illness:
1. The identity of the disease is very important for the patient's behavior, since the symptoms themselves are not sufficient to initiate help-seeking behavior, but labeling could make the difference. For instance, chest pains that are labeled "heartburn" will cause a very different behavior than those labeled "heart attack." Needless to say, that an individual will experience less emotional arousal when the label of their illness indicates a minor physical problem than if it is a more serious illness. The label is, thus, very important since it carries with it information about the problem, a projection as to the length of sickness, and the possible treatment course.

2. The timeline of the illness may not always correspond with the diagnosis. For instance, people with hypertension, a chronic condition, tend to view it as an acute condition, and as such their adherence to treatment and the manner in which they will cope with the illness, will be affected.

3. After a diagnosis, most of us would want to know the cause of the problem, which will affect how we seek treatment and how we will comply with the instructions of the health care professional, and consequently determination of cause is significant. For instance, being told the pain in our leg is a result of a fall would generate a completely different reaction than if we are told it might be bone cancer.

4. Consequences of the disease would probably be clear once a diagnosis is made, although people may incorrectly understand the diagnosis and that may affect the treatment they seek. For instance, many consider a diagnosis of cancer a death sentence, so they will assume the situation is hopeless and will not seek treatment. And actually, if they can be assisted, in many cases they can enjoy more years and possibly good ones.

5. The controllability of a disease has to do with how people view the possibility of treating and controlling the disease. If they, for instance, view the situation as beyond hope, they may not seek treatment, while those who believe medical science can help them will take much more interest in their course of treatment. 
Examining first the effects of loneliness on the body and the immune system, Cohen [6] observed that life events, including separation, loss, and feelings of hopelessness, that are associated with the experience of loneliness affect the endocrine system through abnormal secretion levels from the pituitary and adrenal glands. That may adversely affect the immune system and decrease the body's ability to fight illness and/or result in an increased risk of cancer. That example of deteriorating health through such a process is most probable in people with already compromised immune functioning, especially people with Acquired Immune Deficiency Syndrome (AIDS), an immunosuppressive disease [7]. Research has found that high loneliness scores are associated with significantly lower levels of natural killer cell activity, which are the lymphoid immune cells that play a role in cancer protection and appear to have antitumor and antiviral capabilities [8].

Psychological variables, including loneliness, have been associated with changes in immune functioning and may weaken the body's capacity to fight disease [8]. Kiecolt-Glaser et al. [7] pointed out that more and more research now indicates that psychological factors are clinically significant and are correlated with immunerelated health outcomes, including infectious diseases, cancer, autoimmune diseases, and HIV. People's interconnections with others and their perceptions of such relationships can have a strong influence on physical and mental health [9]. Glaser et al. [10] found that those with social support systems were much healthier whereas those with fewer social ties had increased susceptibility to illnesses [11]. In general, when close relationships are troubled, they are often associated with immune dysregulation [7].

It is now acceptable that people who have well-established social supports seem to be better able to cope with stress and chronic pain. Moreover, social isolation rivaled other well-established risk factors such as cigarette smoking, high blood pressure, obesity, and sedentary lifestyle, as factors in poor health [12]. People with higher rates of social support have better health and lower rates of mortality. It was observed that participants who had the fewest social ties were two to four times more likely to die than those who were well supported [13].

Lynch [14] who wrote extensively on the interface of loneliness and illness, described a study carried out by two researchers at Johns Hopkins University between 1948 and 1964. The researchers followed 1,185 healthy and relatively young medical students and asked them a variety of questions about their families, health, and lifestyle. Later, when those students became physicians, some started to develop serious health problems and others died prematurely. The investigators went back to their data and discovered that the medical students who had developed various cancers prematurely had described their parents as cold and aloof. Another study indicated that people who rated their parents as cold and their relationships with them as strained experienced significant increases in poor health. Results indicated that an astonishing $91 \%$ of those who reported they were not close to their mothers while growing up, developed serious medical problems in midlife, including coronary heart disease, hypertension, ulcers, and alcoholism. Even more remarkable was the finding that $100 \%$ of those who reported that both of their parents were cold and aloof had developed medical problems by midlife. And interestingly, those who reported that they were close to their parents, only $47 \%$ had serious medical problems by the same age [15].

\section{Hospitalization}

When we are sick, in pain, in a medical emergency, or in need of immediate and extensive medical attention, we head to the hospital. Upon entering the health care system, patients in the Western hemisphere benefit from the most contemporary care available, enhanced by modern technology and the expertise of medical staff who have been trained long and hard in regards with the most current information about the human body and the variety of treatments that are available [16]. Despite that, hospitalization can be one of the most distressing events people experience in their lifetime [17]. Brannon \& Feist [12] observed, "When a person enters the hospital as a patient, that person becomes part of a complex institution and assumes a role within that institution. That role includes some difficult aspects: being treated as a 'nonperson,' tolerating lack of information, and losing control of daily activities" (p. 64). It is well known that when people enter the hospital as patients, they become identified by their illness. It is not uncommon to hear a physician telling the nurse to "attend to the multiple fractures in room...." [18].

Illness is a major stressor in one's life [19]. Symptoms put the body into a state of continuous stress that may include pain, fatigue, and, in more severe cases, immobility and even loss of bodily functions and control [20-22]. Additionally, there are factors that negatively affect the patient's psychological state as well. These include perceived threat to one's life, the uncontrollable and unpredictable nature of one's condition, and the state of apprehension and hopelessness, which can have a considerable effect on the patient's thoughts, emotions, and behaviors [2325]. Indeed, the lingering, long-term psychological effects such as anxiety, depression, and post-traumatic stress disorder commonly occur in response to critical illnesses [26,27]. In addition, simple features inherent in the design of hospital environments may negatively influence the process of the patients' recovery, as per [16].

In general, adapting to a hospital environment and routine is often stressful. Having to eat hospital food or having to sleep on different beds may bring about emotional discomfort, as patients no longer "feel at home," and as such have minimal personal control over their choices [28]. There is uncontrollable noise in most hospitals, and it is a significant source of stress for most people. Research has demonstrated that the continuous noise and activity in most hospitals can lead to increased sensitivity to pain and increased need for painkillers in patients and disruptions in the quality of sleep [29]. Inadequate lighting or the absence of welldesigned windows to allow exposure to adequate natural sunlight is yet another factor that has been shown to get in the way of the 
patients' recovery by increasing the occurrence of depression, agitation, and sleep disruptions. Other factors which may be quite disruptive are related to the design of the hospital. Examples are double occupancy rooms that impede the patients' privacy and quality of rest, and the lack of fresh air and poor ventilation systems, can increase the patients' physical and emotional discomfort $[16,28]$.

Lack of social contact is another factor that alienates patients [31]. This is essentially due to the fact that, with the exception of the (limited) visiting time of their family and friends, the hospitalized patients' social contact is limited to interaction with the medical staff. These interactions are obviously unbalanced. On one side, there is the patient, who is powerless, passive, weak, and dependent, and on the other side, are the doctors, nurses, and supporting staff, who are in complete control of almost every aspect of the patient's care, with all the knowledge, authority, and power to influence his life and healing [17].

As a consequence of this enormous gap in power and control in relation to the medical staff, patients may feel even more hopeless and emotionally distressed [31]. One indicator of such a power differential is the frequent use of complex medical jargon by the medical staff that patients are unable to understand [32]. Many patients may experience, in such situations, heightened levels of anxiety as they feel deprived of control over and knowledge about their health and recovery [33]. Data on a sample of hospitalized women indicate that between $10 \%$ and $40 \%$ were subjected to stress at times when the hospital staff disregarded their need for communicating about many aspects of their care [34]. Such perception can result in considerable distress and feelings of helplessness and loneliness in patients [34].

Emotional distance and depersonalization of the patients might be the medical practitioners' natural reactions in dealing with the harsh reality of the hospitalized patients' ill fate and the enormous demands of their responsibilities; it is the only way for them to do their job without feeling burned out or becoming unable to concentrate on treatments [35]. To conclude, medical personnel need to realize that patients are hospitalized for the sake of their bodies, but their needs extend much more than that. They feel frightened, disoriented and powerless in hospitals, and frequently complain about loneliness, which the nursing staff can be trained to help alleviate.

\section{References}

1. McGraw JG (2000) The first of all evils. In: SA Wawrytko \& Rodopi BV (Eds.), The problem of evil. An intercultural exploration Atlanta, Georgia, pp. 145-158.

2. Martens WHJ \& Palermo GB (2005) Loneliness and Associated Violent Antisocial Behavior: Analysis of the Case Reports of Jeffrey Dahmer and Dennis Nilsen. Int J Offender Ther Comp Criminol 49(3): 298-307.

3. Sullivan HS (1953) The interpersonal theory of psychiatry. Norton, NY, USA.

4. Mijuskovic B (1992) Organic communities, atomistic societies and loneliness. Journal of Sociology and Social Welfare 19(2): 147-164.
5. Leventhal H, Leventhal EA, Cameron L (2001) Representations, procedures, and affect in illness self-regulation. A perceptual-cognitive model. In: A Baum, et al. (Eds.), Handbook of health psychology p. 19-47.

6. Cohen IS (1985) Psychosomatic death: voodoo death in modern perspective. Integrative Psychiatry 3(1): 46-51.

7. Kiecolt-Glaser JK, McGuire L, Robles TF, Glaser R (2002) Psychoneuroimmunology: psychological influences on immune function.

8. Kennedy S, Kiecolt-Glaser JK, Glaser R (1988) Immunological consequences of acute and chronic stressors: mediating role of interpersonal relationships. Br J Med Psychol 61( Pt 1): 77-85.

9. Hagerty BM, Williams RA (1999) The effects of sense of belonging, social support, conflict, and loneliness on depression. Nurs Res 48(4): 215219.

10. Glaser R, Kiecolt-Glaser, JK, Bonneau, RH, Malarky W, Kennedy S, et al. (1992) Stress-induced modulation of the immune response to recombinant hepatitis B vaccine. Psychosom Med 54(1): 22-29.

11. Cohen S, Doyle WJ, Skoner DP, Rabin BS, Gwaltney JM (1997) Social ties and susceptibility.

12. Brannon L, Feist J (2004) Health psychology: An introduction to behavior and health. Thomson Wadsworth, Toronto, Canada.

13. Berkman LF, Syme SL (1979) Social networks, host resistance and morality: A nine-year follow-up study of Alameda County residents. Am J Epidemiol 109(2): 186-204.

14. Lynch JJ (2000) A cry unheard: New insights into the medical consequences of loneliness. Bancroft Press, Baltimore, Maryland.

15. Russek L, Schawrtz G (1997) Feelings of parental caring predict health.

16. Rollins JA (2004) Evidence-based hospital design improves health.

17. Hughes B (2001) Psychology, hospitalization, and some thoughts on medical training. European Journal of psychotherapy and counselling 4(1): 7-26.

18. Yarnold PR, Michelson EA, Thompson DA, Adams SL (1998) Predicting patient satisfaction: A study of two emergency departments. J Behav Med 21(6): 545-563.

19. Sellick SM, Edwardson AD (2007) Screening new cancer patients for psychological distress using the hospital anxiety and depression scale. Psychooncology 16(6): 534-542.

20. Incalzi RA, Gema A, Capparella O, Muzzolon R (1991) Effects of hospitalization on affective status of elderly patients. Int Psychogeriatr 3(1): 67-74.

21. Pressman MR, Meyer TJ, Peterson DD, Greenspon LW, Figueroa WG (1997) Effects of hospitalization, surgery, and anesthesia on sleep and biological rhythms. American Psychological Association Washington, USA.

22. Rowe MA (1996) The impact of internal and external resources on functional outcome in chronic illness. Research and Nursing in Health 19(6): 485-497.

23. Mishel MH (1997) Uncertainty in Acute Illness. Annu Rev Nurs Res 15: 57-80.

24. The hospital environment. Journal of Clinical Nursing 7(3): 163-171.

25. Raps CS, Peterson C, Jonas M, Seligman MEP (1982) Patient behavior in hospitals: Helplessness, reactance, or both? J Pers Soc Psychol 42(6): 1036-1041.

26. Seeman TE, Dubin LF, Seeman M (2003) Religiosity/Spirituality and health: A critical review of the evidence for biological pathways. Am Psychol 58(1): 53-63. 
27. Eddleston JM, White P, Guthrie E (2000) Survival, morbidity, and quality of life after discharge from intensive care. Crit Care Med 28(7): 22932299.

28. Scragg P, Jones A, Fauvel N (2001) Psychological problems following ICU treatment. Anaesthesia 56 (1): 9-14.

29. William AM, Dawson S, Kristjanson LJ (2008) Exploring the relationship between personal control and the hospital environment. J Clin Nurs 17(12): 1601-1609.

30. Topf M (1992) Effects of personal control over hospital noise on sleep. Res Nurs Health 15(1): 19-28.

31. Rokach A, Brock H (1996) The causes of loneliness. Psychology: Journal of Human Behavior 33(3): 1-11.

32. Attree M (2001) Patients' and relatives' experiences and perspectives of 'Good' and 'Not so Good' quality care. J Adv Nurs 33(4): 456-466.
33. Phillips D (1996) Medical professional dominance and client dissatisfaction: a study of doctor-patient interaction and reported dissatisfaction with medical care among female patients at four hospitals in Trinidad and Tobago. Soc Sci Med 42(10): 1419-1425.

34. Williams AM, Irurita VF (2005) Enhancing the therapeutic potential of hospital environment by increasing the personal control and emotional comfort of hospitalized patients. Appl Nurs Res 18(1): 22-28.

35. Polimeni A, Moore S (2002) Insight into women's experiences of hospital stays: perceived control, powerlessness and satisfaction. Behavior Change 19(1): 52-64.

36. Tattersall AJ, Bennett P, Pugh S (1999) Stress and coping in hospitals. Stress Medicine 15(2): 109-113.
Creative Commons Attribution 4.0

International License

For possible submissions Click Here
Submit Article

\section{Psychol Psychother Res Stud \\ Benefits of Publishing with us}

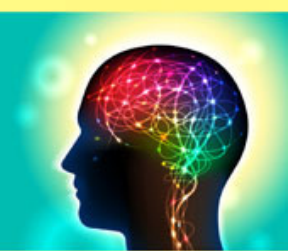

- High-level peer review and editorial services

- Freely accessible online immediately upon publication

- Authors retain the copyright to their work

- Licensing it under a Creative Commons license

- Visibility through different online platforms 